\title{
Predation on a Slender Anole (Anolis fuscoauratus) by a Whip Scorpion (Order Amblypygi)
}

Oliver Thomas

Department of Biosciences, Swansea University, Swansea, SA2 8PP, UK (olliethomas444@gmail.com)

$\mathrm{T}^{\mathrm{b}}$ he Slender Anole (Anolis fuscoauratus D'Orbingy 1837) is an arboreal, diurnally active species of lizard that attains a snout-to-vent length of about $50 \mathrm{~mm}$ (Carvajal-Campos and Ayala-Varela 2019). This species is distributed east of the Andes throughout northern South America (Ecuador, Colombia, Peru, Bolivia, Brazil, and the Guyanas). In the Ecuadorean Amazon, it is most frequently encountered in the understory of primary rainforests, although it also exploits more disturbed areas, basking or displaying in tree falls or patches of open forest or sleeping at the edges of trails on small branches and leaves 1-2 $\mathrm{m}$ above the ground (Vitt et al. 2003).

Amblypygids, or whip scorpions, are members of the class Arachnida, order Amblypygi. They are generally nocturnal and considered to be sit-and-wait predators that take a variety of prey, rather than active foragers seeking specific targets. Amblypygids prey primarily on invertebrates (Chapin and Hebets 2016), but reports document predation on small vertebrates such as lizards, frogs, and even birds (Weygoldt 2000; Owen and Cokendolpher 2006; Chapin and Hebets 2016).

On 27 July 2019 I was conducting a night-time visual encounter survey with student volunteers on the "Mystery Trail" located in the camping area of the Sani Reserve, Sucumbios, Ecuador. At 2046 h, we encountered an amblypygid (Heterophrynus sp.) low on the trunk of a small tree next to the trail $\left(-0.440251^{\circ},-76.310325^{\circ}\right)$ with a captured adult male $A$. fuscoauratus in its pedipalps (Fig. 1). The arachnid appeared to have killed its prey by pushing its head back and using its fang-like chelicerae to bite into the throat of the anole. We found no other puncture marks on the anole. Based on the time of the encounter, the portion of

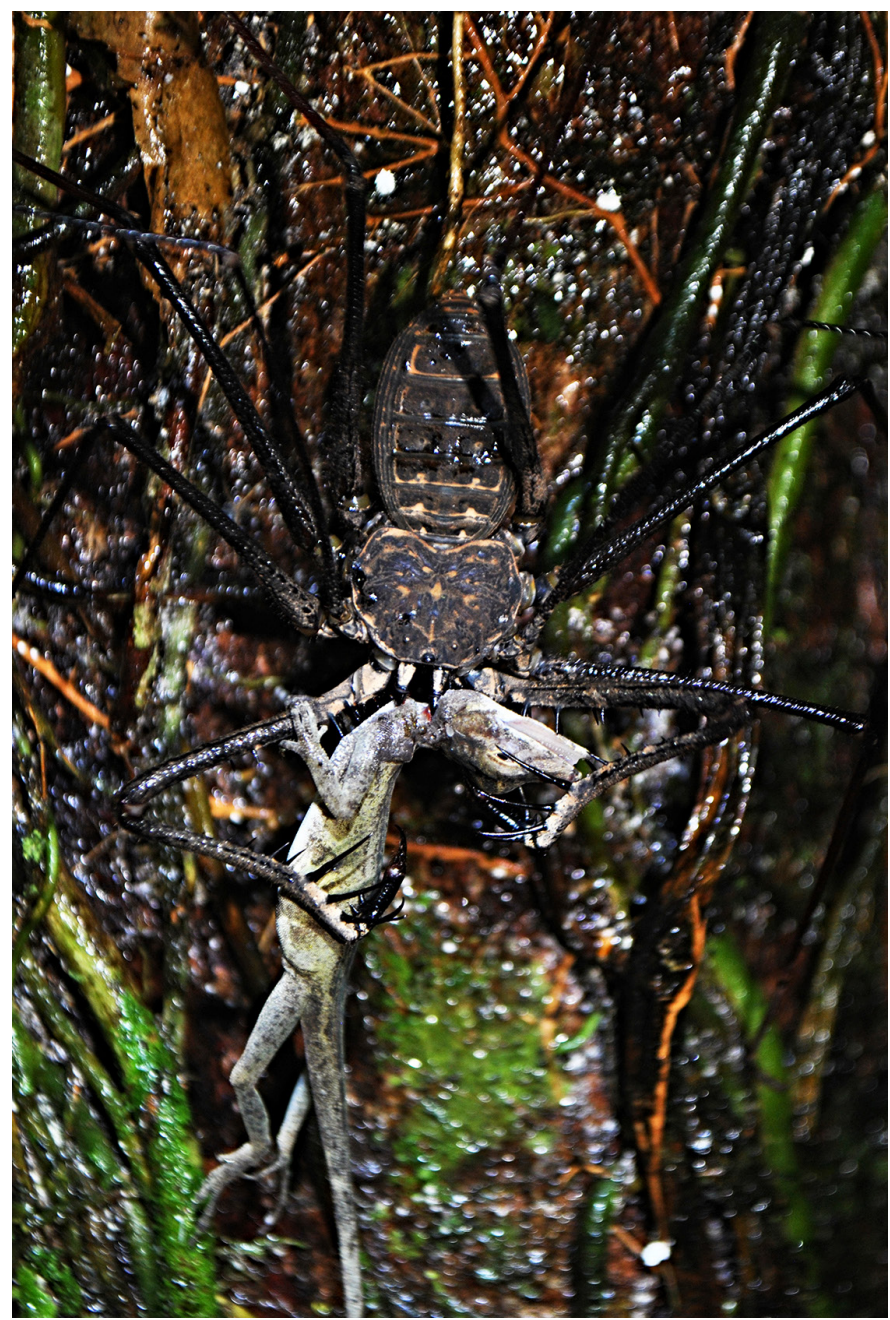

Fig. 1. An amblypygid (Heterophrynus sp.) eating a Slender Anole (Anolis fuscoauratus) on 27 July 2019 in the Sani Reserve, Sucumbios, Ecuador. Photograph by the author. 
the lizard that had been consumed, and the fact that these lizards tend to search for sleeping locations in the early evening (pers. obs.), the amblypygid probably encountered and captured the anole while it was asleep. Although records exist of predation on lizards by whip scorpions, this observation definitively adds amblypygids to the list of known predators of $A$. fuscoauratus.

\section{Acknowledgements}

I thank Operation Wallacea for providing the opportunity to conduct wildlife surveys and the Cardinal Vaughan Memorial School, whose students joined us in camp that week. Thanks also to the Sani Lodge and community for their aid as guides and for their continued belief in maintaining their forest for the preservation of its biodiversity.
Thanks to Giselle Mangini for help with an earlier draft of this manuscript.

\section{Literature Cited}

Carvajal-Campos, A. and F. Ayala-Varela. 2019. Anolis fuscoauratus. In: O. TorresCarvajal and D. Salazar-Valenzuela, 2017. Reptiles del Ecuador. Version 2019.0. Museo de Zoología, Pontificia Universidad Católica del Ecuador. <https://bioweb.bio/faunaweb/reptiliaweb/FichaEspecie/Anolis\%20fuscoauratus>.

Chapin, K.J. and E.A. Hebets. 2016. The behavioral ecology of amblypygids. The Journal of Arachnology 44: 1-15.

Owen, J.L. and J.C. Cokendolpher. 2006. Tailless Whip Scorpion (Phrynus longipes) feeds on Antillean Crested Hummingbird (Orthorhynchus cristatus). The Wilson Journal of Ornithology 118: 422-424.

Vitt, L.J., T.C.S. Avila-Pires, P.A. Zani, S.S. Sartorius, and M.C. Espósito. 2003. Life above ground: Ecology of Anolis fuscoauratus in the Amazon rain forest, and comparisons with its nearest relatives. Canadian Journal of Zoology 81: 142-156.

Weygoldt, P. 2000. Whip Spiders (Chelicerata: Amblypygi): Their Biology, Morphology and Systematics. Apollo Books, Stenstrup, Denmark. 